\title{
SOBRE DISTRAÍDOS Y PAVOS: ESCRITURA Y SUJETO EN Alejandro Rossiy Fabián CASAS
}

ABOUT THE ABSENT-MINDED

AND TEENAGERS: WRITING AND SUBJECT

IN ALEJANDRO ROSSI AND FABIÁN CASAS

Ana Cecilia Olmos

ORCID 0000-0003-0870-7492

Universidade de São Paulo

São Paulo, SP, Brasil

\section{Resumen}

Este artículo propone una lectura de Manual del distraido (1978) de Alejandro Rossi y Diarios de la edad del pavo (2017) de Fabián Casas atendiendo a los modos de inscripción del sujeto en prácticas de escritura que, al apelar a diferentes registros de lo autobiográfico, expanden los límites de lo literario hacia zonas de indeterminación discursiva que borran las distinciones entre escritura y vida. Aunque no son ajenos a una idea de literatura moderna, estos desplazamientos parecen asumir otras inflexiones en los días de hoy. Buscando visibilizarlas, este artículo pretende no apenas señalar la disparidad inevitable entre libros publicados con 40 años de diferencia, sino también indagar, en el gesto autobiográfico de sus escrituras, prefiguraciones del presente y/o persistencias de una modernidad literaria en crisis.

Palabras clave: escrituras híbridas, subjetividad, Alejandro Rossi, Fabián Casas.

\section{Resumo}

Esse trabalho propóe uma leitura de Manual del distraido (1978) de Alejandro Rossi y Diarios de la edad del pavo (2017) de Fabián Casas, atendendo aos modos de inscrição do sujeito em práticas de escrita que, ao apelar a diferentes registros do autobiográfico, expandem os limites do literário para zonas de indeterminação discursiva que apagam as distinçôes entre escrita e vida. Ainda que sejam reconhecíveis numa ideia de literatura moderna, esses deslocamentos parecem assumir outras inflexóes nos dias de hoje. Buscando visibilizá-las, esse trabalho pretende não apenas assinalar a disparidade inevitável entre livros

\section{Abstract}

This article proposes a reading of Manual del distraído (1978) by Alejandro Rossi and Diarios de la edad del pavo (2017) by Fabián Casas, focusing on the ways that subjects are inscribed in writing practices that, appealing to different autobiographical registers, expand the limits of the literary to areas of discursive indeterminacy that erase the distinctions between writing and life. Although they are not removed from the idea of modern literature, these expansions seem to take on other inflections today. With the aim to make them visible, this article seeks not only to point out the inevitable disparity between books published 40 
publicados com 40 anos de diferença, mas também indagar, no gesto autobiográfico de suas escrituras, prefigurações do presente e/ou persistências de uma modernidade literária em crise.

Palavras Chave: escritas híbridas, subjetividade, Alejandro Rossi, Fabián Casas years apart, but also to reveal, within the autobiographical gesture of its writings, prefigurations of the present and/or the persistence of a literary modernity in crisis.

Keywords: hybrid writings, subjetivity, Alejandro Rossi, Fabián Casas

Las intervenciones críticas de las últimas décadas no han dejado de señalar la diseminación de escrituras que, en la tentativa de estrechar sus vínculos con la vida, se desplazan con singular versatilidad entre la ficción y otros discursos y lenguajes. Se trata de prácticas que, al apelar a diferentes registros de lo autobiográfico (diarios, crónicas, ensayos, fotografías, etc) expanden los límites de lo literario hacia zonas de indeterminación discursiva que borran las distinciones entre escritura y vida, narración y experiencia, imaginación y realidad ${ }^{1}$. Aunque estos desplazamientos no son ajenos a una idea de literatura moderna que, sabemos, en un cuestionamiento permanente de sus formas y límites, buscó restituir las relaciones entre arte y vida, estas expansiones hacia lo vital asumen otras inflexiones en los días de hoy. Buscando visibilizarlas, este ensayo propone una lectura de Manual del distraido (1978) de Alejandro Rossi y Diarios de la edad del pavo (2017) de Fabián Casas atendiendo, en particular, a los modos de inscripción del sujeto en la escritura. No se trata de establecer una perspectiva comparada que señale apenas la disparidad inevitable entre libros publicados con 40 años de diferencia, sino de indagar, en el gesto autobiográfico de sus escrituras, prefiguraciones del presente y/o persistencias de una modernidad literaria supuestamente en crisis.

\section{Escritura y distracción}

En los años 70, Octavio Paz invitó a Alfredo Rossi a escribir una columna mensual en la revista Plural. La colaboración era libre, no estaba condicionada a ninguna disciplina, tema o forma específica. De esa manera inesperada, relata Rossi en su ensayo "Comienzo de un libro", se expandieron los dominios de la especialización en filosofía en la que se había movido hasta ese momento y se abrió un espacio para su afición, largamente postergada, pero siempre latente, por la literatura. Bajo el título Manual del distraido, la columna fue la posibilidad de empezar a escribir, dice el autor, "sin fines

1 Me refiero en líneas generales a estudios críticos tales como Una intimidad inofensiva (2016) de Tamara Kamenszain, Mundos en común (2015) de Florencia Garramuño, Espectáculos de realidad (2007) de Reinaldo Laddaga, El giro autobiográfico de la literatura argentina actual (2008) de Alberto Giordano, Formas hibridas (2017) de Rafael Gutiérrez, Escritas de si, escritas do outro (2007) de Diana Klinger, entre otros. 
claros ni propósitos específicos, movido únicamente por una intensa e íntima satisfacción" (ROSSI, 2005, p. 571). Si bien varias de las colaboraciones siguieron las pautas del ensayo en las que se inscribe el gesto reflexivo de la enunciación filosófica, la gratuidad de esa escritura dilató el campo de exploración hacia formas narrativas que, en un límite impreciso con la ficción, movilizan recuerdos, insinúan confesiones, revelan afinidades o deliran ficciones teóricas acerca de la literatura. En esa diversidad, todos los textos, aclara el autor, "intentaban ser ejercicios de tono y ritmo" (ROSSI, 2005, p. 571). La decisión de reunir esos materiales en un libro llegó algunos años después, al percibir que "a pesar de la variedad, había por lo menos dos rasgos comunes: respeto al lenguaje y una especie de broma de la vida interior o comedia de la conciencia" (ROSSI, 2005, p. 572).

El libro, que se publicó en 1978 con el título Manual del distraído, se ofrece, entonces, como un espacio discursivo indisciplinado en el que coexisten textos de diferente extensión (de la reflexión demorada a la anotación breve), que abordan temas variados (la literatura, la filosofía o la política se mezclan con la anécdota personal) y que juegan con la versatilidad de las formas, explorando un umbral borroso entre el ensayo, el cuaderno de notas, el relato autobiográfico y la ficción. Una imprecisión discursiva que propicia el estrechamiento de los vínculos entre escritura y vida por medio de una rara mezcla de narración de la experiencia, desarrollo de la argumentación e invención imaginaria que alía los dos intereses de Rossi, la filosofía o, como él dice, "ese hedonismo de la inteligencia" que le permitió experimentar "auténticas hazañas imaginativas", y la literatura, no apenas como conjunto de obras, sino, más bien, como "una disposición humana" que lo pone en contacto con la realidad y le provee "la gramática básica para estar en el mundo" (ROSSI, 2005, p. 499).

"Por varias razones" es uno de los textos de Manual del distraído en el que esa indeterminación discursiva que cruza el gesto autobiográfico con la especulación intelectual y la invención imaginaria alcanza una acabada expresión. En las primeras líneas, en un tono levemente irónico, el autor se figura a sí mismo no como filósofo, condición que remite a un ejercicio profesional, ni como pensador, término ambiguo y sospechoso de cierta presunción, sino apenas como "una persona que piensa", es decir, alguien para quien el pensar se confunde con la vida misma. "Vivir sin pensar - afirma es una contradicción; pensar sin hacerlo con ahínco, con perseverancia, sin voltear hacia la derecha y hacia la izquierda, es un disparate" (ROSSI, 2005, p. 177). El pensar, que Rossi describe como "una racionalidad laboriosa y modesta" atenta a "la ilimitada variedad de factores que intervienen en la más pequeña de nuestras acciones", supone, por tanto, una indagación permanente y minuciosa de la experiencia cotidiana. La ironía que permea el texto crece y roza la burla cuando el escritor, en un claro gesto de ridiculización de sí 
mismo, afirma que esa racionalidad está muy lejos de garantizarle un equilibrio emocional, al contrario, afirma, se asemeja más a "la seriedad desesperada del roedor" (ROSSI, 2005, p. 180).

El relato de una experiencia personal, la carta que le envió a su hermano para pedirle un préstamo, es el episodio que escruta de manera pormenorizada para ejemplificar ese pensar en acto que es común a todos porque es constitutivo de la vida. La escritura de la carta, ante una situación delicada e impostergable, ha exigido planear cuidadosamente cada uno de sus aspectos, intentando predecir, en la dimensión fantasmática que todo diálogo epistolar comporta, las reacciones del destinatario, un otro que no por familiar es menos misterioso. No me voy a detener en los detalles de esa especulación que, por cierto, no está privada de humor. Lo que me interesa señalar es esa deriva de la escritura desde las elucubraciones teóricas hacia la narración de la experiencia personal y, sobre todo, la sutil toma de distancia ante la autoridad del saber o la presunción del pensamiento, que esa deriva comporta. Ni como filósofo, ni como pensador, Rossi incita a pensar desde la vida misma, desde una "épica de lo cotidiano" que recupere para el pensar su carácter de acontecimiento y ponga en valor su singularidad. $\mathrm{Al}$ respecto, Rossi es enfático: "Mi experiencia -créanme- es definitiva: cualquier acción -pensada a fondo- es un pozo que conduce al centro de la tierra. Cuando se logra esta visión, ya no importa demasiado lo que sucede; la vida entera se convierte en algo denso y aventurero" (ROSSI, 2005, p. 177).

Como sugiere Miguel Morey en su libro Psiquemáquinas (1990, p. 41), el pensar no se asimila a la construcción sólida del saber en base a esquemas y estructuras, por el contrario, en tanto acontecimiento singular, es la fuerza o la energía que abre nuevos caminos, instaurando la posibilidad de una articulación otra de la experiencia del sujeto. Es esta la condición del pensar que, en la indeterminación discursiva de sus textos, Rossi reivindica, no solo como acto constitutivo de la vida, sino también como perspectiva crítica al ordenamiento del saber que imponen los dispositivos de la cultura. Gustavo Guerrero reflexiona en este sentido cuando señala que la escritura de Rossi, en ese diálogo peculiar que establece entre literatura y filosofía, forja una estética "que prefiere buscar sus verdades a través de la descripción de la experiencia cotidiana y no apelando a la revelación de una realidad más elevada cuyo conocimiento estaría reservado al escritor de genio, al gran intelectual o al poeta visionario" (GUERRERO, 2012, p. 172).

"Relatos" es el título de otro de los textos de Manual del distraído en los que se juega una variante de la relación entre escritura y vida ${ }^{2}$. Se trata

2 Rossi experimenta también con los límites entre autobiografía y ficción en su libro Edén. Vida imaginada, en el que a través de Alejandro (una suerte de alter ego adolescente del autor) relata el desplazamiento entre países, culturas y lenguas que marcó su primera juventud (ROSSI, 2006) 
de una reflexión sobre el relato con que Rossi narraba el viaje de la familia de Italia hacia Venezuela cuando estalla la guerra, en 1942, y que él solía exponer, con entusiasmo teatral, en ocasiones sociales. No se trata apenas de la narración de ese viaje transatlántico como una puesta en forma de lo vivido, sino de una indagación sobre la forma particular que ese relato asumía cada vez que lo reiteraba. El análisis meticuloso de qué es lo que el relato cuenta, cómo lo cuenta (el tono, el ritmo narrativo, los detalles que contribuyen a la verosimilitud), y también lo que omite o, mejor, lo que no consigue decir, tejen una trama metanarrativa que cruza lo público, lo privado y lo íntimo de esa experiencia juvenil en la búsqueda de una verdad otra, ya no aquella del relato tantas veces repetido. Si lo público y lo privado, es decir la referencia a la guerra y la vida familiar, son la materia maleable en el relato, parece ser lo íntimo lo que lleva al cuestionamiento de su forma narrativa. César Aira sostiene que lo estrictamente opuesto a lo público no es lo íntimo, como se tiende a creer, sino lo privado. La intimidad sería, más bien, una especie de "suplemento recóndito de lo privado", que él define como "un campo extra de formato indefinido que apela a los afectos" y que, por tratarse de algo informe, resiste al lenguaje. "La frontera de la intimidad -dice este autor- retrocede tanto como avanza la voluntad de contarla" (AIRA, 2008: 8). Esa resistencia de la intimidad al lenguaje es la que parece reconocer Rossi cuando, al visitar una vez más el relato de aquel viaje, afirma: "Esta es la crónica habitual, cierta sin duda, pero en la cual no encuentro la furia de mis recuerdos y mi decisión de no imaginar el porvenir. Tampoco está allí el desánimo creado por ciertas conversaciones críticas acerca de Italia; un lento proceso de erosión que me dejaba exhausto y vacío" (ROSSI, 2005, p. 43). Que la intimidad permanezca inexpresada parece ser uno de los costos de este relato y, sobre todo, uno de los motivos de su caducidad, sin embargo, el autor no deja de admitir la seducción que esa forma del relato, que aspiraba a "la compulsión del cuento policíaco y la minucia de un retrato antiguo", ejercía sobre sí y, tal vez, sobre la audiencia.

La narración avanza, entonces, en función de una no coincidencia de la enunciación con el relato, es decir, el sujeto narra su experiencia desde una posición de enunciación en constante despliegue hacia la otredad de sí mismo. Aunque cuenta la historia una vez más y refiere situaciones de la vida a bordo, Rossi analiza cada una de las estrategias narrativas puestas en juego y no deja de preguntarse por qué el relato no se dirige directamente a la íntima verdad de esa experiencia: "Por qué no se decide a encarar el final de la historia sin caracoleos artísticos?” (ROSSI, 2005, p. 47). No sin cierto suspenso, las últimas líneas de esta versión analítica del relato se precipitan hacia un desenlace relativamente sorprendente que desvenda una verdad de lo vivido antes no percibida o, hasta ese momento, imposible de ser enunciada. 
Más allá del rasgo autobiográfico de este texto, lo que quiero destacar es ese desdoblamiento del sujeto de enunciación en el que se puede reconocer lo que señala Juan Villoro cuando afirma que, en Rossi, "narrar es comentar" y que, en ese cruce entre narración y comentario, donde filosofía y literatura se encuentran, su escritura funda una suerte de "epistemología del relato" en la que "presenciar los sucesos equivale a argumentarlos, en el doble sentido de interpretarlos y trabarlos en una historia" (VILLORO, 2000, p. 48).

Esa peculiar estrategia narrativa se puede reconocer también, aunque con otro tono, en los últimos textos del Manual del distraido ${ }^{3}$; un conjunto de ficciones en los que un escritor enfrenta sus miedos, obsesiones y miserias personales en busca de la idea genial que le permita escribir la Gran Obra y ganar el reconocimiento del público. Se trata de una parodia mordaz de la sociabilidad literaria que encarna este escritor junto a las figuras de Gorrondona, un crítico "miope e impotente" que juzga la literatura desde categorías reductoras, y del también aspirante a escritor Leñada, "un alma meticulosa y académica" que vive arrinconada en su timidez. El narrador desdeña ese mundillo literario, sin embargo no desiste de sus tentativas para alcanzar el reconocimiento. La puesta al día de su hacer literario evoca irónicamente las teorías más experimentales de la literatura de los años 70. Las hipótesis teóricas de narrar "sin sujeto" y "sin misterio", o de reducir la literatura a un "lenguaje en situación" que el narrador expone, no solo ridiculizan sus inútiles esfuerzos, sino que, sobre todo, hacen visible la perspectiva escéptica de Rossi que, con ironía, se burla, en la parodia de la propia figura de escritor, de las vanidades de la escena literaria y, por extensión, del hombre y su mundo.

Esa perspectiva irónica permea muchos de los textos de Rossi y, se podría decir, el propio escritor alude a ella cuando se refiere, en otro de sus ensayos, a la figura de Juan de Mairena, aquel profesor apócrifo inventado por Antonio Machado que, a contramano de las formas disciplinadas de transmisión del conocimiento que la institución docente profesa, practica una pedagogía abierta, desorganizada e irreverente en la que la ironía es convocada para desmantelar las presunciones del saber. Para Mairena, dice Rossi, "la ironía es el disfraz de su inseguridad, el reverso de su impotencia social, el arma para atacar lateralmente, la consecuencia de un cierto escepticismo frente a las teorías, la huída del idioma sonoro, el pudor ante la asertividad y el recurso para sobrevivir entre imbéciles" (ROSSI, 2005, p. 190). No sería exagerado imaginar, proyectada en la ironía de Mairena, una de las posiciones de escritura preferidas de Rossi.

Con este pasaje por algunos de los textos del Manual del distraído solo quiero poner en evidencia la indeterminación de una escritura que si bien

3 Me refiero a los textos "Con Leibniz", "Sin sujeto", "Sin misterio" y "Ante el público" que cierran el volumen (ROSSI, 2005, p. 244-275) 
moviliza modos discursivos que propician las relaciones entre literatura y vida, no deja de refractarlas en un juego de desplazamientos de la enunciación que hace que el sujeto que escribe emerja en su descentramiento constitutivo, es decir, nunca idéntico a sí mismo y en permanente proceso de desaparición. Se trata de un sujeto de enunciación "móvil y escurridizo" que, tal como señala Héctor Libertella, coloca a la escritura en el centro de una escena en donde ese sujeto no cesa de desaparecer. "Quien quiera que sea el autor de este libro -dice Libertella- él no sabe que, aunque desee ser capitán de su alma, el resultado de sí mismo es el de un perpetuo desgobernado, porque las certezas no le vienen del arriba que ayuda, sino de ese abajo del manuscrito donde todos, casi siempre, terminan desprendidos por completo de los proyectos y las ideas previas" (LIBERTELLA, 1993, p. 146).

No es otra la figura de ese "perpetuo desgobernado" sino la que cifra, irónicamente, el título del libro: Manual del distraído. Expresión paradójica que anuncia una escritura dispersa que, lejos del ordenamiento y la instrumentalización del saber que profesa el manual, se hace de desvíos permanentes, se distrae y avanza en diferentes direcciones, seducida por el detalle y lo ocasional. Es en este sentido que "el abajo del manuscrito" destituye al sujeto en tanto conciencia de sí y lo despoja de toda intencionalidad y dominio.

Afín a esta dispersión escritural que descentra la enunciación, desjerarquiza saberes y mezcla formas, Rossi declara su preferencia por "los libros sin secuencias rígidas, sin severidades escolares, esos textos que, sin remordimientos, podemos abrir en la página que nos dé la gana" (ROSSI, 2005, p. 184) y rescata, en la ficción de Juan de Mairena o en el recuerdo de Jorge Portilla, "esas figuras que, al margen de las instituciones oficiales, ejercen una pedagogía desordenada e incitante, que angustia y desnuda a quienes se mueven entre el manual y el manual" (ROSSI, 2005, p. 102) Descentrada, aunque en estrecha relación con la experiencia, la escritura de Rossi desvía, con el gesto gratuito de la distracción, ahí donde la cultura ordena, jerarquiza e instrumentaliza.

\section{Escritura e inmadurez}

En su libro Una intimidad inofensiva (2016), Tamara Kamenszain nos recuerda que las vanguardias destronaron la concepción sustancialista del sujeto y postularon su presencia en el texto en términos de posición enunciativa, dando lugar a un vaciamiento del yo que propició la centralidad de la escritura en la literatura moderna. No hace falta insistir en esta relación entre sujeto y escritura para reconocer el linaje moderno en el que se inscribiría la literatura

4 Se trata del ensayo In memoriam, texto incorporado a Manual del distraido, que Rossi escribe a veintitrés años de la muerte de Jorge Portilla (ROSSI, 2005, p. 102-107) 
de Rossi, la cual, aunque apele a formas discursivas habitualmente ligadas a la expresión del yo (la narración autobiográfica, el ensayo, la anotación breve, etc), despliega un juego de posiciones enunciativas que despoja al sujeto de cualquier atributo propio, pertenencia o intencionalidad. Ese vaciamiento del yo, que Kamenszain entiende como la "dosis sacrificial" necesaria para el ejercicio del arte en la modernidad, estaría dando señales de agotamiento en algunas poéticas contemporáneas que buscan restituir al sujeto en el texto "pero ya no a la manera centralista y autoritaria de aquel incuestionado yo autoral, sino en un estado de apertura tal que, salido de sí, confunde sus límites con el mundo que se hace presente en esa operatoria" (KAMENSZAIN, 2016, p. 11). Se trata, sostiene Kamenszain, de una suerte de "post-yo" que, al establecer una relación de continuidad entre escritura y experiencia, se inscribe en el texto en función de una "actitud performativa" que tiende a borrar la distinción entre literatura y vida, a fundir escritura y mundo 5 .

Como variante de esta inflexión del modo en que el sujeto se inscribe en la escritura que, con agudeza, postula Kamenszain para algunas poéticas contemporáneas, propongo una aproximación a Diarios de la edad del pavo de Fabián Casas. Poeta reconocido en la actualidad y autor de ensayos y narrativas, Casas dio a conocer en 2016, sin recortes, directamente transcriptos, los diarios que escribió en los ańos 90 , cuando iniciaba su tránsito por la literatura ${ }^{6}$. Aunque la trayectoria literaria de Casas e, incluso, ciertas posiciones acerca de la escritura presentadas en sus ensayos, dificulten una rápida identificación de estos diarios con las poéticas performativas que se diseminan en los días de hoy, creo que es posible acercarse a ellos en esta clave de lectura e incluso preguntarnos si no fue esta posibilidad de lectura la que estimuló su publicación. Por cierto, esto no impide considerarlos también con relación a una larga tradición de diarios de escritores que, más allá de la singularidad que el registro del transcurrir de los días asume en cada caso, exhibe los motivos que usualmente llevan al escritor hacia esta forma de expresión (protegerse de las aflicciones del mundo, hacer un ejercicio confesional, trabajar un estilo propio, construir una imagen de autor, testimoniar una época, etc). A este repertorio de motivos, se suma "el tópico de la dificultad de escribir" que, como explica Alberto Giordano, solo surge en los diarios de escritor a partir del siglo XIX, cuando la escritura comienza a ser valorada en sí misma, más allá de su función instrumental. "Desde entonces -dice este autor- una de

5 Aunque Kamenszain moviliza esta hipótesis de lectura tanto en poetas como narradores, en la medida en que esa indistinción entre escritura y mundo disuelve también los límites de las formas literarias, en este caso en particular interesan los abordajes de las narrativas de Marcelo Matthey, Mario Levrero y Alejandro Zambra que, con variantes, apelan al formato del diario íntimo.

6 Los diarios comprenden el período de marzo de 1992 a diciembre de 1997 y fueron publicados por primera vez, en 2016, por la editorial Eloísa Cartonera. En 2017, los publicó nuevamente Emecé, del grupo editorial Planeta. 
las funciones manifiestas de los diarios íntimos es la búsqueda de soluciones a esa dificultad a través del registro de sus múltiples variantes, desde las más obvias a las más misteriosas" (GIORDANO, 2006, p. 146).

Los diarios de Casas visitan varios de los motivos habituales del género; en esas páginas, la angustia de los apremios económicos se entrecruza con el mundo, a veces perturbador, de los afectos; los recuerdos irrumpen ante cualquier detalle de la vida cotidiana; el comentario de las lecturas con frecuencia se alía a los estados de ánimo; la referencia a los trabajos y los proyectos, que no siempre coinciden, parece tejer una precaria red de contención para la existencia. Sin embargo, es el tópico de la dificultad de escribir el que adquiere una mayor evidencia en el registro de los días, con la particularidad, además, de remitir, en términos literarios, al momento de la vida aludido en el título, la edad del pavo, ese período de transición entre la infancia y la vida adulta o, como dice Casas, "el momento en que uno está adolesciendo desde la literatura, cuando tiene que construirse como escritor, como una etapa de incertidumbres, indolencia y entusiasmo" (CASAS, 2016). La recurrencia de este tema en Diarios de la edad del pavo hace evidente la condición de una escritura que no se postula como un trabajo en el interior del lenguaje y con relación a él, sino como una actividad que se constituye en relación directa con la experiencia del sujeto, afectada por la vida y confundida con ella ${ }^{7}$. En este sentido, a la manera de esas escrituras performativas a las que se refiere Kamenszain, en las que la pulsión de la experiencia desplaza el trabajo en el interior del lenguaje, lo que los diarios de Casas dan a leer es "el descarte de lo que merece ser pasado a la letra escrita” (KAMENSZAIN, 2016, p. 23). Casas lo explicita cuando afirma: "Este diario es mi retrete" (CASAS, 2017, p. 29); o cuando, declarando el carácter antiliterario de esa escritura, ajena a la exploración de un estilo, confiesa: "Es un diario que me da vergüenza" (CASAS, 2017, p. 57); e, incluso, cuando aleja esa escritura del trabajo creativo: "Este diario, tal vez, sea ese espacio para poder escribir sin estructurar" (CASAS, 2017, p. 91).

Aunque la reflexión metadiscursiva también sea un tópico frecuente del diario de escritor (la pregunta sobre las razones que lo llevan a escribir un diario, la función que este tiene en su vida, etc) y la actitud performativa no deje de ser un rasgo que constituye al género, creo que es posible leer Diarios de la edad del pavo en relación con las poéticas contemporáneas a las que se refiere Kamenszain, porque tal vez sea en este marco, que propicia una determinada perspectiva de lectura, que se explique la decisión de publicar esta escritura

7 En lo que se refiere a esta relación entre escritura y experiencia, Kamenszain dialoga con las ideas de Florencia Garramuño que, en sus libros La experiencia opaca (2009) y Mundos en común (2015), señala que, en algunas poéticas contemporáneas, la escritura es atravesada por una "pulsión experiencial" que excede la forma estética y lleva a la literatura a un cuestionamiento de su autonomía. 
íntima que no estaba destinada a tal fin. Aún más si se considera el estrecho diálogo que este libro establece con Ocio, la novela de Casas publicada diez años antes, en 2006, en la que varias referencias autobiográficas expuestas en estos diarios se presentaban en clave ficcional. La publicación de estos diarios no supondría, por tanto, la exhibición de una intimidad antes cifrada en la ficción, sino más bien la posibilidad de leerlos ahora como parte de un conjunto de escrituras que, confundidas con la vida misma, cuestionan el dominio de lo literario.

Leídos en estos términos, como "el descarte de lo que merece ser pasado a la letra escrita", los diarios sólo pueden insistir en el registro de la indolencia, la inseguridad y la impotencia que Casas siente ante la escritura. De una manera pueril cuando dice "...me siento como un mono que durante las noches, en su jaula del zoológico, aprende a hablar" (CASAS, 2017, p. 27); o más libresca cuando escribe: "Tengo en mi cabeza una música que no puedo tocar $i Q u e ́$ frase! En este tipo de aseveraciones se encuentra la ontología de la inmadurez del escritor" (CASAS, 2017, p. 55). Referencia que retorna unos días después cuando registra: "Piglia, en Respiración Artificial, escribe la frase que dice uno de sus personajes: "Escucho una música; pero no la puedo tocar", así me siento desde hace tres días. Escucho una música; pero no tengo la fuerza de ponerme a escribirla" (CASAS, 2017, p. 58). La apatía y la impotencia de este escritor que adolesce desde lo literario se objetiva, aquí, en la referencia a la aporía de la forma y la inmadurez en el arte que Gombrowicz formula en el prólogo a Ferdydurke. Aún bajo el riesgo de reducir la cuestión, conviene sintetizar el planteo: las formas acabadas de la cultura, sostiene el escritor polaco, no se corresponden con la realidad íntima del sujeto y le impiden manifestar por vía directa su inmadurez, a la que solo le resta el silencio; al mismo tiempo, si el sujeto solo exterioriza lo que está maduro en él a través de las formas acabadas de la cultura, esta se reduciría a un juego mecánico y perdería el contacto con la vida. Ante la imposibilidad de encontrar la forma para la inmadurez, lo que queda es tomar distancia frente a la forma -sugiere este autor- y conseguir así una mayor libertad de palabra en el campo de la cultura (Cf. GOMBROWICZ, 2004, p. 15-23). La escritura de descarte del diario, entonces, como la búsqueda de la forma para la inmadurez ${ }^{8}$.

Para concluir, no se trata simplemente de identificar la escritura indolente de Diarios de la edad del pavo ("Escucho una música; pero no tengo la fuerza de ponerme a escribirla") y la escritura distraída de Rossi, a la que

8 En la entrada del miércoles 24 de julio de 1996, el escritor registra: "Toda la terapia de ayer giró en torno de mi bloqueo 'literario'. Cuando escribo esta palabra ya siento asco de ella. 'Literario"' (CASAS, 2017, p. 315) 
él se refiere como una escritura "sin planes, sin pretensiones cósmicas y con amor al detalle", en tanto tomas de distancia frente a las formas acabadas de la cultura. Es preciso atender al particular modo de inscripción del sujeto en cada una de ellas. Si en la escritura descentrada de Rossi el yo, disperso en un juego de posiciones enunciativas, no cesa de desaparecer, en los diarios de Casas, la fusión de la escritura con la experiencia delinea un sujeto que, como dice Kamenszain, lo que afirma es "más un estar en el mundo que un ser en la literatura" (2016:59). A propósito, en uno de los fragmentos de Zettel, Libertella señala esta inflexión de las relaciones entre escritura y sujeto: "Musil se refería al hombre sin atributos. Hoy se empieza a hablar del 'posthombre', alguien que, al no tener lectura ni interpretación, no opera entonces como un censor de las cosas sino como un sensor, una célula fotoeléctrica que solo las registra y hasta se da razón por ellas" (LIBERTELLA, 2009, p. 31). Cabría preguntarse si entre el censor y el sensor no se juega la diferencia entre los sujetos de escritura que se diseñan en estos libros. Pero, más allá de esto, conviene insistir en lo que cifran estas figuras del distraído y del pavo, en tanto instancias de escritura que remiten, como dice Gombrowicz, a la lucha personal con las formas. Tal vez, la única posibilidad de la literatura.

\section{Referencias}

AIRA, César. La intimidad. Boletín del centro de estudios de Teoría y Crítica Literaria. 13-14. Rosario, Universidad Nacional de Rosario, 2008, p.6-12.

CASAS, Fabián. Diarios de la edad del pavo. Buenos Aires: Emecé, 2017.

CASAS, Fabián. "Escribía para sentirme bien, este diario era una especie de tranquilizante", F. Casas. 29/06/2016. https://www.telam.com.ar/ notas/201606/153356-fabian-casas-diario-cultura.html Acesso em 09/07/2020

GIORDANO, Alberto. Una posibilidad de vida. Escrituras intimas. Rosario: Beatriz Viterbo, 2006.

GUERRERO, Gustavo. Alejandro Rossi: un ensayista en la frontera. In: Castilleja, D. et all. El ensayo hispánico: cruces de géneros, sintesis de formas. Genève: Droz, 2012, p. 167-176.

GOMBROWICZ, Witold. Prólogo. Ferdydurke. Trad. Witold Gombrowicz Buenos Aires: Seix Barral, 2004, p.15-23

KAMENSZAIN, Tamara. Una intimidad inofensiva. Los que escriben con lo que hay. Buenos Aires: Eterna Cadencia, 2016. 
LIBERTELLA, Héctor. Alejandro Rossi, la identidad en disolución. In: Las sagradas escrituras. Buenos Aires: Sudamericana, 1993, p. 145-148.

LIBERTELLA, Héctor. Zettel. Buenos Aires: Letranómada, 2009

MOREY, Miguel. Psiquemáquinas. Barcelona: Montesinos, 1990.

ROSSI, Alejandro. Obras reunidas. México: FCE, 2005.

VILLORO, Juan. Pensar distrae. In: Efectos personales. Barcelona: Anagrama, 2000, p. $42-52$.

Ana Cecilia Olmos. Professora livre-docente de Literatura Hispano-Americana na Universidade de São Paulo e pesquisadora do CNPq. Especialista em literatura hispanoamericana, concentra sua pesquisa nos discursos críticos, a narrativa contemporânea e o ensaio de escritores. Autora de Por que ler Borges (2008) e Escritas descentradas (2019), assim como de múltiplos artigos em revistas especializadas. Organizou os títulos, Em primeira pessoa. Novas abordagens de uma teoria da autobiografia (com Helmut Galle et all) e Textualidades transamericanas e transatlânticas (com Elena Palmero González). Atualmente desenvolve uma pesquisa sobre escritas breves, híbridas e fragmentárias na literatura hispano-americana dos séculos XX e XXI.

E-mail: anaolmos@usp.br 